\title{
El Segundo Congreso Internacional de Historia de América.
}

La iniciativa de los Congresos de Historia de América partió del Instituto Histórico y Geográfico del Brasil, prestigiosa institución que dió su molde a varias de las de nuestro continente, efectuándose la primera reunión en Río de Janeiro el 7 de setiembre de I922, en conmemoración del primer centenario de la independencia del Brasil.

En este certamen se dividió el Congrese en una sesión general de Historia de Aniérica yl èn tantas seccionse especiales cuantas son las partes en que políticamente se halla dividida la América, constituída por estados independientes, colonias o dominios de estados europeos. Cada uno de estos grupos contaba con un presidente, un secretario, un relator y dos vocales y realizaba su labor examinando los trabajos presentados, elevándolos con informe a la consideración del Congreso, en las dos secciones plenas que se llevaron a cabo y en las cuales se trató, también, cuestiones de carácter general.

En este orden de trabajo, el Congreso a propuesta del ilustre historiador y jurista brasileño Dr. Affonso Celso, aprobó el plan según el cual debía ser escrita la historia de América, que fué el siguiente: 
Historia Geográfica y Etnográfica.

„ Política y Administrativa.

„ Militar.

„ Judicial.

„ Económica y Financiera.

, Diplomática.

, Científica.

, Literaria.

, Pedagógica.

, Artística.

, Religiosa.

„ General (Síntesis histórica).

En este Congreso se acordó establecer en las facultades de Filosofía y Humanidades de América, seminarios e institutos de investigación a fin de preparar los repertorios bibliográficos generales y seccionales de la Historia de América y de cada uno de sus estados, recomendándose, igualmente, la reunión de congresos de archiveros de cada país al efecto de llevar a cabo una labor de relevamiento de los archivos históricos. También se acordóla adepción de un tipo de ficha internacional bibliográfican para facilitar el canje de publicaciones, la fundación de un Comité Internacional Americano para reunir todas las formas del folklore y las melodías populares, la publicación de un gran atlas histórico de América y la formación de una sección especial de Historia en las bibliotecas de las embajadas o legaciones acreditadas en las naciones americanas.

A propuesta del suscrito, que tuvo el honor de representar en ese certamen a la Universidad Mayor de San Marcos, el Congreso considerando el deber de toda asociación americana, representativa de intereses públicos de declarar los principios de justicia internacional, necesarios pa= ra la unidad moral del continente, acordó, en sesión plena, emitir un voto de repudio contra los sistemas de fuerza y de 
conquista, y de adhesión a las normas de derecho público como condición de verdadera paz y efectivo progreso. A igual proptiesta y en sesión semejante, acordó el Congreso la creación de la cátedra de Historia de América en las universidades en que faltare, definió el papel de estos institutos en orden a la investigación histórica y resolvió que al escribirse y enseñarse la Historia de América se considerara todo cuanto representa contribución del pensamiento humano a la obra de la civilización, haciendo así visible la influencia de las ideas en la vida histórica de los pueblos.

El Congreso designó como sede de la próxima reunión la ciudad de Buenos Aires, pronunciándose a favor de la creación de institutos de investigación histórica con sede en Madrid y Lisboa, aconsejando para su realización que las universidades de las capitales de los estados americanos contribuyeran con una cuota especial. También se señaló a Wáshington, México, Lima, Montevideo y Río para que en estas ciudades funcionaran oficinas permanentes de investigación histórica. Los trabajos presentados fueron numerosos y han sidopublicados en valrios volúmenes, por el Instituto Histórico yJ Geográfico del Brasileque, justamente va a celebrar, el año venidero, en forma solemne, el centenario de su fundación.

En cumplimiento de lo acordado en Río de Janeiro, se ha reunido últimamente en Buenos Aires el Segundo Congreso Internacional de Historia de América, bajo los auspicios de otra no menos ilustre institución: La Junta de Historia y Numismática Americana, que preside el eminente historiador argentino Dr. Ricardo Levene, ligado a nuestra Facultad de Letras por el merecido título que se le confiriera de doctor "honoris causa".

El Congreso se dividió en las secciones que se anota a continuación:

Historia del Arte. " Literaria. 
Historia Política y Económica.

Militar, Naval y Sección Numismática.

Metodología de la Enseñanza (sesión plenaria).

Historia Filosófica, Científica y Religiosa.

Historia Jurídica y Diplomática.

Concepto e interpretación de la Historia de América. Fuentes de la Historia americana: Archivos, Museos y Bibliotecas.

Para el trabajo en cada sección se designó, con anticipación al Congreso, tres o cuatro oradores llamados a disertar sobre tópicos relacionados con la índole de la sección.

Los discursos de orden no podían, reglamentariamente, ser materia de discusión, pero en ocasiones ellas se promovieron en forma animada sin que se votase conclusiones puesto que no era potestativo hacerlo sino al Congreso en sesión plena.

Los principales temas desarrollados por los oradores en las respectivas secciones fueron los siguientes: "Las Primeras Sociedades Literafias Argentinas"; "Ideas e ideales de los partidos y teñdeneiass quie adtúan en el coampo de lo político del Reyno de Indias desde I808 hasta I810"; "La enseñanza de la Historia Americana"; "La enseñanza de Historia en los planes de estudios desde Mitre hasta nuestros días"; "La oratoria sagrada y política en el Brasil"; "Historia Filosófica Argentina"; "Historia Jurídica Americana y Argentina"; "Historia Diplomática del Brasil y Méjico"; "Concepto e interpretación de la Historia de América y técnica de bibliografía"; "Historia del Arte Hispano-americano"; "Interpretación económica de la época colonial"; "Valor y calidad de las fuentes de información histórica en períodos de anormalidad política"; "Concepto interpretativo sobre Historia de América"; Historiografía Cuyana y Congresos de Historia Regionales"; "Concepto moderno de los Museos". Además, se repartió un folleto intitulado "Po- 
nencias de Rafael Altamira sobre metodología de la enseñanza de la Historia de América”.

Las secciones funcionaban en locales correspondientes a su índole, facilitando en esta forma a los delegados el conocimiento de universidades, museos, etc., que de otra manera no les habría sido fácil visitar.

Separadamente se efectuaron tres reuniones plenas: la inaugural, realizada en forma solemne, con asistencia del Presidente de la nación argentina; la segunda reunión fué de la sección Metodología de la Enseñanza, a la que concurrieron todos los congresales; y, finalmente, la tercera sesión plena fué la de clausura, aprobándose en ella varias mociones de carácter general, una muy importante sobre revisión de textos de Historia de América para conseguir que sin falsear los hechos históricos se stiprima de aquellos todo cuanto pueda herir la dignidad de los países de nuestro continente, los mismos que se adherirán para ello al convenio que ya existe celebrado, sobre esta materia, entre la Argentina y el Brasil.

A iniciativa del delegado uruguayo, Dr. José Salgado ratificó el Congreso la ponencia aprobada en el primer certamen efectuado en Río para que, por cuota de todos los países americanos, se erija un monumento conmemorativo en el campo de Ayacucho.

El Congreso, como queda dicho, estuvo presidido por el doctor Ricardo Levene, quien, dando pruebas de excepcionales dotes de inteligencia, sagacidad y laboriosidad, presidió todas las reuniones habidas, tanto las de sección como las sesiones plenas.

No es posible dejar de mencionar, también, a los argentinos Emilio Ravignani, Director del Instituto de Investigaciones Históricas; Mario Belgrano, Secretario del Congreso; Luis Mitre, Director Honorario del Museo de su nombre; Arturo Capdevila; Enrique Martínez Paz, Presidente de la Junta de Historia y Numismática, filial de Cór- 
doba; Diego Luis Molinari; Juan Mantovani, Inspector General de Segunda Enseñanza; el historiador mendocino Manuel G. Lugones y el arquitecto Martínez de Noel y Enrique Gandía. También vienen a la memoria, entre otros, el académico y Embajador de México Alfonso Reyes; el historiador de Arte Mexicano Manuel Toussant; el boliviano Alcides Arguedas; los uruguayos Felipe Ferreyro, Presidente del Instituto Histórico y Geográfico de su país, Buenaventura Caviglia y José Salgado; el paraguayo Justo Pastor Benites; los académicos del Brasil Max Fleiuss y Pedro Calmón; los de Chile, Luis Barros Borgoño, Domingo Amunátegui Solar y Ricardo Donoso; el ecuatoriano José 'Gabriel Navarro y el venezolano José Santiago Rodríguez quien aludió, brillante y oportunamente, a la necesidad de que cese la emulación que ha existido al escribir la historia de los héroes de la emancipación americana en sus dos grandes campos, el colombiano y el argentino.

La Delegación Pertuana estuvo integrada por el Embajador del Perú en la Argentina doctor Felipe Barreda y Laos, quien lappiresidió, dos doctores Horacio H. Urteaga y el que escribe este artículo, representantes del Gobierno del Perú y de la Universidad de San Marcos; el doctor José Uriel García, representante de la Universidad del Cuzco y el doctor Pedro Villar Córdova de la Universidad Católica de Lima.

El doctor Barreda y Laos disertó sobre "Enseñanza de la Historia Americana" y a nombre de todas las delegaciones pronunció un discurso en la Universidad de Buenos Aires dando respuesta al Rector de la misma Universidad. E1 invitado de honor y representante de nuestra Universidad, doctor Urteaga, disertó sobre "Concepto e interpretación de la Historia de América y técnica de bibliografía", habiendo el Congreso recomendado que los métodos por él empleados en la publicación de las fuentes históricas peruanas sirvan de modelo a quienes publiquen fuentes históricas de 
los siglos XVI, XVII y XVIII. El doctor Uriel García se ocupó de "El valor del arte peruano, sus creaciones y estilos en la época del incanato y en el período colonial" y también de "Las nuevas direcciones del arte neo-colonial y de la influencia del arte aborigen en la arquitectura contemporánea del Perú" y el mismo, en unión del doctor Pedro Villar Córdova, intervinieron ampliamente en el debate habido para que en los futuros congresos de Historia de América se comprenda la Proto Historia y la Pre Historia.

Todos los trabajos e intervenciones de los delegados mencionados merecieron calurosa aprobación del Congreso.

Juzgando necesario dar realce al rol de nuestra Universidad Mayor en esta asamblea, en la que figuraba una sección de historia científica, presente un trabajo sobre la Universidad Mayor de San Marcos de Lima desde su fundación hasta la fecha $\mathrm{y}$, dando cumplimiento a un acuerdo de la Comisión organizadora del Congreso, presenté, también, en la última sesión plena, un informe sobre los trabajos presentados a la consideración de la Asamblea acerca del "Concepto e interpretacién cle da Historias de América". Fuentes de la Historia Americana Archivos, Bibliotecas y Museos". Igualmente, teniendo en mira hacer efectivos los acuerdos del Congreso, formulé, en la sesión plena referida, la ponencia siguiente:

El Congreso Internacional de Historia de América, con el fin de hacer efectivos sus acuerdos y votos;

\section{Resuelve:}

Que se constituya en la ciudad que resulte sede del próximo Congreso una oficina que, en relación con la comisión organizadora del actual Congreso, se encargue de hacer conocer a los gobiernos e instituciones históricas americanas, señalando su significado y su utilidad, todas las proposiciones aprobadas en este certamen, siendo también atribución de la oficina en referencia: 
a) Procurar que se cree en las universidades, en las que aun faltare, la cátedra de Historia de América.

b) Procurar, también, que cada país de América remita a la biblioteca de las universidades de los otros países los libros de historia nacional y americana que se publiquen en su territorio.

c) Solicitar de todos los profesores de Historia de América de las universidades americanas sus programas de enseñanza y hacerlos conocer a los profesores de las demás naciones.

d) Gestionar que los países americanos se adhieran al convenio sobre revisión de textos escolares, celebrado entre Argentina y Brasil.

e) Gestionar el envío, por parte de todos los países americanos, de una lista que contenga sus monumentos históricos, a fin de que la oficina pueda servir de órgano para reclamar de la destrucción o descuido de los mismos.

f) Servir de intermediario entre los profesores de los respectivos países que hagan seminario, para que se pongan de acuerdo acerca de los temas de investigación del año, a fin de que no se estudie el mismo punto por dos o más profesores a la vez.

g) Recomendar a los gobiernos americanos la publicación de las fuentes inéditas o de las ya publicadas, pero agotadas.

h) Las demás atribuciones que respondan a la indole de la oficina, la que dará cuenta al próximo Congreso de la forma cómo hubiere cumplido este acuerdo.

Tal ha sido en síntesis la labor del II Congreso Intermacional de Historia de América, conmemorativo del cuarto centenario de la fundación de la ciudad de Buenos Aires, llevado a cabo, como he indicado, bajo los auspicios de la Junta de Historia y Numismática Americana que fundara el ilustre general Bartolomé Mitre, estadista y hombre de 
Letras, el creador en la república Argentina, según Gandia, de los modernos estudios históricos.

Doce reuniones brillantes y eruditas y gran número de trabajos presentados, acreditan un aporte histórico considerable, que podrá apreciarse debidamente cuando se publiquen los anales de la importante y fraterna asamblea.

Sin embargo, como toda obra es susceptible de mejoramiento, sin restar mérito a la extraodinaria labor de este certamen, pienso que en la próxima reunión podrá verse forma de que el Congreso se pronuncie sobre temas históricos que son objeto de controversia entre los historiadores americanos.

Esto requiere un mayor número de sesiones plenas, que las efectuadas en los Congresos de Río y Buenos Aires.

Evidentemente que las sesiones plenas entregadas a la iniciativa de todos los congresales se aproximan al caos, pero si se realizaran ajustándose a un programa previo este peligro no existiría.

El caso podría resolverse haciéndose conocer con anticipación, por la comisión organizadora del próximo Congreso, un programa que comprendiera unos diez puntos o temas para ser discutidos y votados en sesiones plenas.

Aclemás, así como en la reunión habida se designaron con anterioridad diversos oradores, se nominaría, en cambiọ, miembros informantes sobre los puntos o temas cuestionables y en una sesión preparatoria se elegirían comisiones para que opinaran escuchando al informante, y en la sesión plena se pondría en debate el dictamen emitido por la comisión, sin permitir tratarse de asuntos distintos al señalado. A conocimiento de las comisiones irían, como han ido en la asamblea de Buenos Aires a conocimiento de las secciones, los trabajos presentados.

Creo no equivocarme al afirmar que en el Conf reso, que acaba de clausurarse flotaba el anhelo de que jas asambléa diera en definitiva su voto sobre los temas que, tan concep-

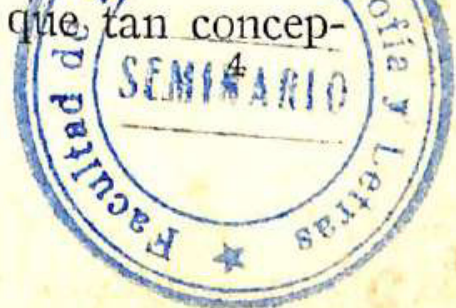


tuosamente fueron desarrollados por los oradores señalados al efecto.

El sistema propuesto hacía factible la intervención de los congresales que quisieran tomar parte en el debate, la misma que reglamentariamente quedaría restringida a los nombrados de antemano para hablar en las reuniones parciales.

Corresponde a la Comisión Organizadora del III Congreso Internacional de Historia de América, que deberá reunirse dentro de cuatro años en la ciudad de Santiago, ver si estas sugerencias merecen ser consideradas.

\section{Lima, agosto de I937.}

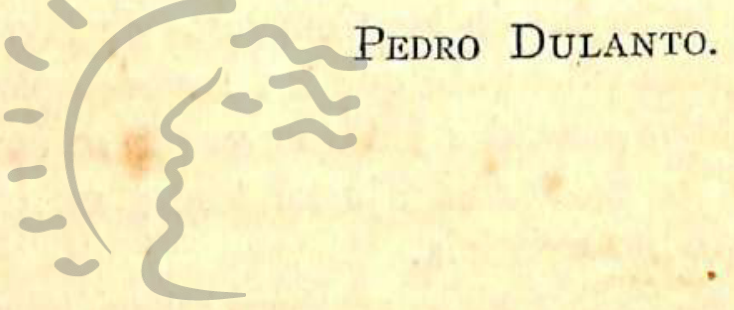

\section{Biblioteca de Letras} "Jorge Puccinelli Converso"

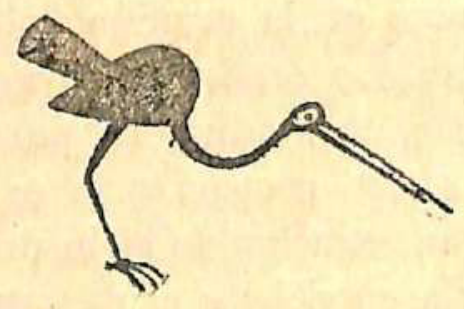

